\title{
Graves' Disease in 100 Cases in Conakry: Epidemiological, Clinical, Therapeutic, and Evolutionary Aspects
}

\author{
Naby Moussa Baldé1*, Amadou Kaké1, Djibril Sylla², Alpha Mamadou Diallo1, \\ Mamadou Mansour Diallo', Mamadou Alpha Diallo', Amadou Diango', Lanciné Kourouma', \\ Elhdj Zainoul Bah1, Mamadou Chérif Diallo1, Kadija Dieng1, Mody Abdoulaye Barry ${ }^{1}$ \\ ${ }^{1}$ Department of Endocrinology and Diabetes, Donka Conakry University Hospital, Conakry, Guinea \\ ${ }^{2}$ Department of Internal Medicine, Donka Conakry University Hospital, Conakry, Guinea \\ Email: *naby.balde@diabeteguinee.org
}

How to cite this paper: Baldé, N.M., Kaké, A., Sylla, D., Diallo, A.M., Diallo, M.M., Diallo, M.A., Diango, A., Kourouma, L., Bah, E.Z., Diallo, M.C., Dieng, K. and Barry, M.A. (2022) Graves' Disease in 100 Cases in Conakry: Epidemiological, Clinical, Therapeutic, and Evolutionary Aspects. Open Journal of Endocrine and Metabolic Diseases, $12,75-81$.

https://doi.org/10.4236/ojemd.2022.122005

Received: January 6, 2022

Accepted: February 25, 2022

Published: February 28, 2022

Copyright $\odot 2022$ by author(s) and Scientific Research Publishing Inc. This work is licensed under the Creative Commons Attribution International License (CC BY 4.0).

http://creativecommons.org/licenses/by/4.0/ (c) (i) Open Access

\begin{abstract}
Context and Objective: Graves' disease is an autoimmune disorder of the thyroid gland that occurs in genetically predisposed individuals. It represents the most frequent cause of hyperthyroidism with a clear female predominance. The objective of our work was to report the sociodemographic, clinical, therapeutic, and evolutionary characteristics of Graves' disease at the University Hospital of Conakry. Methods: This was a cross-sectional, descriptive study, over the period from December 2016 to June 2021, at the endocrinology consultation of Donka University Hospital. Epidemiological, clinical, therapeutic, and evolutionary variables of patients followed up for Graves' disease were collected and analyzed. The diagnosis of Graves' disease was based on the presence of clinical signs of thyrotoxicosis, diffuse goiter, exophthalmos, and or T-RAK positivity. Results: Graves' disease was related to $33 \%$ of thyroid consultations and $64 \%$ of hyperthyroidism. The sex ratio $\mathrm{M} / \mathrm{F}$ was 0.07 . The median age of the patients was $39.4 \pm 13$ years. The main reason for consultation was thyrotoxicosis syndrome, dominated by cardiovascular signs (92\%). TRAK was performed in 38 patients with a positive result in $89 \%$, i.e., a mean level of $17.93 \mathrm{mUI} / \mathrm{l}$. All patients were treated with synthetic antithyroid drugs, with a favorable clinical evolution. Surgery was considered in 4 patients after the stabilization of the thyroid function. The follow-up was considered regular in 49 patients (49\%). Conclusion: Graves' disease is the most frequent hyperthyroidism in Conakry with a clear predominance of women, especially young women. Efforts should be focused on improving diagnosis and the access to treatment for better patient compliance.
\end{abstract}

\section{Keywords}

Autoimmunity, Thyroid, Graves’ Disease, Conakry 


\section{Introduction}

Hyperthyroidism is one of the most common endocrine disorders. Graves' disease, is an autoimmune disorder of the thyroid gland that occurs in genetically predisposed individuals. It is the most frequent cause of hyperthyroidism, with a clear female predominance. It is characterized by the presence of anti-TSH receptor antibodies. It is classically manifested by signs of hyperthyroidism, homogeneous goiter, and sometimes ophthalmopathy [1] [2].

Graves' disease represents a variable percentage of diagnosed hyperthyroidism from one country to another, but it always remains high. In Cameroon, it represents $82 \%$ of hyperthyroidism [3] and 72\% in Senegal [4]. Its diagnosis is often simple and its early management allows avoiding the evolution towards numerous complications, namely cardiovascular. Nevertheless, treatment remains difficult and relies on a therapeutic arsenal combining synthetic anti-thyroid drugs, radioactive iodine therapy, and surgery [5]. In Guinea, no recent study has been published on the prevalence of Graves' disease. Thus, the objective of this study was to report the sociodemographic, clinical, therapeutic, and evolutionary characteristics of Graves' disease at the University Hospital of Conakry.

\section{Method}

This was a cross-sectional, descriptive study of patients followed for Graves' disease at Donka University Hospital from December 1, 2016, to June 30, 2021. All patients followed up in the department for Graves' disease were included. No patient was excluded.

Peripheral thyrotoxicosis was defined as the presence of clinical manifestations of thyrotoxicosis associated with increased thyroid hormone levels (free T3 and free T4) and decreased TSHus levels.

The diagnosis of Graves' disease was based on the presence of clinical signs of thyrotoxicosis, diffuse goiter, exophthalmos, and/or TSH receptor antibody positivity.

The patients were questioned (age, gender, profession, residence, family, and personal history) and systematically examined for goiter, signs of thyrotoxicosis, compression (dysphagia, dysphonia, cough, and dyspnea), and cardiothyreosis (heart failure and rhythm disorder).

According to the clinical context, a complementary exploration was proposed. These included hormonal exploration (TSHus, free T3 and free T4), inflammatory assessment (sedimentation rate, C-reactive protein, blood count), immunological assessment (anti-TSH receptor or TRAK), and imaging, particularly cervical ultrasound with determination of the TIRADS (Thyroid Imaging Reporting and Data System) classification [6] and thyroid scintigraphy.

Epidemiological, clinical, therapeutic, and evolutionary variables of the followedup patients were collected and analyzed. Informed consent was obtained for the collection and analysis of patient and anonymity was in accordance with the principles of scientific writing. The data were collected using a questionnaire, entered, 
and analyzed using SPSS version 23 software.

\section{Results}

Between December 2016 and June 2021, 300 patients were consulted in the Endocrinology Department of Donka University Hospital for a thyroid problem. Among them 156 patients (52\%) were hyperthyroid. Graves' disease was the main etiology and concerned 100 patients (64\%). Women represented $93 \%$ of the cases, with a sex ratio M/F of 0.07 . The medium age of the patients was $39.4 \pm 13$ years and the age group 31 to 40 years was the most affected (30\%). According to the socio-professional categories, civil servants were the most represented (33\%), followed by housewives (31\%), workers in the informal sector $(20 \%)$, and pupils/students (12\%). More than half of the patients (65\%) resided in Conakry, the capital city, as opposed to $35 \%$ who came from the cities inside the country. The average delay of consultation of the patients in our service was 2 years. The thyrotoxicosis syndrome dominated symptoms (Table 1), with cardiovascular signs being the most frequently found, namely palpitation and dyspnea, respectively in $92 \%$ and $84 \%$ of cases. Goiter (Table 2) was noted in 94 patients, i.e., $94 \%$ of cases, and a vascular murmur were found in $62 \%$ of cases. Exophthalmos was found in 67 patients $(67 \%)$ of which $10 \%$ were unilateral. Pretibial myxedema was noted in 28 patients (28\% of cases). Graves' disease was associated with other autoimmune pathologies in 3 cases: 2 cases of vitiligo and one case of rheumatoid arthritis.

Graves' disease was associated with diabetes mellitus in $8 \%$ and hypertension in $22 \%$. Cardiothyreosis was the main complication found (6\%). The hormonal assessment was performed in 91 patients (91\%) and TSH was lower in all patients. The mean TSH level was $0.09 \mathrm{u} U \mathrm{UI} / \mathrm{ml}$ with extremes from 0.001 to 0.14 ųUI/ml.

Table 1. Distribution of functional signs in the 100 patients with Graves' disease in the endocrinology department from December 2016 to June 2021.

\begin{tabular}{lc}
\multicolumn{1}{c}{ Symptoms } & Percentage (\%) \\
\hline General: & 89 \\
- Weight loss & 89 \\
- Physical asthenia & \\
\hline Cardiovascular: & 98 \\
- Palpitations & 98 \\
- Dyspnea & \\
\hline Neuropsychiatric: & 91 \\
- Nervousness & 68 \\
- Insomnia & 81 \\
- Thermophobia & \\
\hline Digestive: & 58 \\
- Acceleration of the transit &
\end{tabular}


Table 2. Distribution of physical and associated signs in the 100 patients with Graves' disease in the endocrinology department from December 2016 to June 2021.

\begin{tabular}{lc}
\hline \multicolumn{1}{c}{ Signs } & Percentage (\%) \\
\hline Thyrotoxicosis & 91 \\
- Hand Wetness & 91 \\
- Osteotendinous hyperreflexia & 83 \\
- Tremors & 92 \\
- Tachycardia & \\
\hline Associated Signs & 94 cases, vascular 62 cases \\
- Goiter & 67 cases \\
- Bilateral exophthalmos & 28 cases \\
- Pre-tibial myxedema
\end{tabular}

Anti TSH receptor antibodies were performed by 38 patients, the result was positive in $89 \%$, i.e., a mean level of $17.93 \mathrm{mIU} / \mathrm{l}$ for extremes from 1.7 to 44 IU/l. Thyroid ultrasound was performed in 77 patients (77\%). TIRAD III was the most represented (51\%).

All patients were treated with synthetic antithyroid drugs, with a favorable clinical course. Beta-blockers were prescribed in 77 patients (77\%) and anxiolytics were prescribed in 65 patients $(65 \%)$.

Thyroid surgery was considered in 4 patients after stabilization of thyroid function. One patient with iatrogenic hypothyroidism was substituted with levothyroxine until thyroid function stabilized. Follow-up was considered regular in 49 patients (49\%).

Six patients $(6 \%)$ relapsed when the treatment was stopped. This relapse was observed on average after 18 months. These patients had a large goiter. A total of 27 patients (27\%) were lost to follow-up during treatment.

\section{Discussion}

This study reflects the hospital data on Graves' disease in our country. However, it had limitations related to the sample size, the high cost, and the local unavailability of some complementary explorations, especially immunology. As a result, diagnostic certainty could not be established in all cases. Furthermore, the data cannot be extrapolated to the entire Guinean population.

\subsection{Socio-Demographic Aspects}

In this study, Graves' disease was the most frequent etiology of hyperthyroidism (64\%). A similar frequency was found by Baldé et al. [7] in 2007 in Conakry.

In this study, there was a clear predominance of women (93\%) with a sex ratio of 0.07 . Graves' disease is essentially a female disease. In the literature, a frequency of 7 to 10 women for one man is reported [7] [8]. The medium age of our patients was $39.4 \pm 13$ years with a peak between 31 and 40 years. This confirms that Graves' disease remains a disease of the young adult. Sixty-five percent of the patients lived in the capital city, which could be explained by the choice of the urban site of the 
study, but also by the inaccessibility of patients living within the country to care, especially to specialized care.

\subsection{Clinical and Paraclinical Aspects}

The more or less complete thyrotoxicosis syndrome was intense with a predominance of general, cardiovascular, and neuropsychological signs. The frequency of associated signs such as goiter, exophthalmos, and myxedema are in agreement with the data of the literature [4] [7] [8].

In our series, Graves' disease was associated with diabetes in $10 \%$, with one case of vitiligo and one case of rheumatoid arthritis. This could suggest the possibility of a link between autoimmune pathologies. The prevalence of association with arterial hypertension (30\% of cases) reflects the frequency of this pathology in the general population [9].

Several authors have reported a frequent observation of cardiothyreosis during hyperthyroidism: 6\% in our series, $13 \%$ in Conakry [7] and Dakar [10], and $26.57 \%$ in Lomé [11]. This cardiothyreosis would occur more frequently in elderly subjects or with a delay in diagnosis and management. It is said to be more serious when the subject has pre-existing heart disease [7] [8].

Hormonal assessment, in particular TSHus, was performed in $91 \%$ of patients. This frequency is higher than the $46.66 \%$ found by Akoussou et al. [11] in Togo in 2001 and the 70\% found by Baldé et al. [7] in 2017 in Guinea.

The immunological workup, anti-TSH receptor antibodies (TRAK) were performed in 38 patients and the result was positive in $89 \%$ of cases, i.e., a mean level of $17.93 \mathrm{mIU} / \mathrm{l}$ with extremes of 1.7 to $44 \mathrm{IU} / \mathrm{l}$. This immunological test was performed abroad for patients who had the means to do so. In Sub-Saharan Africa, the high cost of investigations, particularly immunological ones, and the inadequacy of the local technical facilities are limiting factors for their prescription. However, according to the literature, TSH receptor antibodies offer more than $90 \%$ of diagnostic sensitivity, especially in the absence of exophthalmos [8].

\subsection{Therapeutic and Evolutionary Aspects}

The therapeutic strategy of Graves' disease is different in different institutions and continents. In developing countries, the poor accessibility and the lack of availability of thyroid exploration means increase the difficulty in establishing therapeutic indications for hyperthyroidism. Radioactive iodine treatment is rarely available in Africa, which limits treatment options to synthetic antithyroid drugs and surgery. In contrast, in the United States of America, 69\% of patients receive radioactive iodine therapy as first-line treatment [8].

Carbimazole was rapidly effective in correcting the symptoms of hyperthyroidism with a favorable short-term course. However, compliance with current treatment regimens (12 to 18 months) is poor in Africa, and treatment discontinuation is frequent. The number of patients lost to follow-up is high: $27 \%$ in our study, $65 \%$ in the series reported in Togo [11], 23.7\% in Senegal [4]. Moreover, the quality of therapeutic follow-up is made difficult by the absence or high cost of hormonal 
monitoring.

Only $4 \%$ of our patients underwent surgery after stabilization of thyroid function. In Senegal, Dieudiou D et al. [8] in their study reported a frequency of thyroidectomy of $14.5 \%$. Madieng et al. [12] in a series of 402 thyroidectomies in general surgery reported a frequency of $25.3 \%$ of Graves' disease. None of our patients had received radioactive iodine treatment because it was not available. Therapy for thyrotoxicosis in African countries appears mainly limited to surgery and antithyroid drugs.

\section{Conclusion}

Graves' disease is the most common form of hyperthyroidism in Conakry with a clear predominance of women, especially young women. Its clinical manifestations are classic. Prolonged medical treatment with Carbimazole is the preferred therapeutic option. Nevertheless, compliance with this treatment is poor, treatment breaks are frequent, and the number of patients lost to follow-up is high. A comprehensive thyroid management program, including training for general practitioners and the access to medications, is needed to improve diagnosis, treatment, and patient compliance.

\section{Conflicts of Interest}

The authors declare no conflict of interest.

\section{References}

[1] De Leo, S., Lee, S.Y. and Braverman, L.E. (2016) Hyperthyroidism. The Lancet, 388, 906-918. https://doi.org/10.1016/S0140-6736(16)00278-6

[2] Tomer, Y. and Davies, T.F. (2003) Searching for the Autoimmune Thyroid Disease Susceptibility Genes: From Gene Mapping to Gene Function. Endocrine Reviews, 24, 694-717. https://doi.org/10.1210/er.2002-0030

[3] Nouedoui, C., Moukouri, E., Juimo, A.G., Zok, F.D.A., Pagbe, J.J., Sosso, M., et al. (1999) Les hyperthyroïdies à Yaoundé-Cameroun: Quelques aspects épidémiologiques, étiologiques et thérapeutiques: Bilan de notre expérience. Médecine d Afrique Noire, 46, 193-198.

[4] Diagne, N., Faye, A., Ndao, A.C., Djiba, B., Kane, B.S., Ndongo, S., et al. (2016) Aspects épidémiologique, clinique, thérapeutique et évolutif de la maladie de Basedow en Médecine Interne au CHU Ledantec Dakar (Sénégal). Pan African Medical Journal, 25, Article No. 6. https://doi.org/10.11604/pamj.2016.25.6.7868

[5] Smithson, M., Asban, A., Miller, J. and Chen, H. (2019) Considerations for Thyroidectomy as Treatment for Graves Disease. Clinical Medicine Insights. Endocrinology and Diabetes, 12, PMID: 31040734. https://doi.org/10.1177/1179551419844523

[6] Tappouni, R.R., Itri, J.N., McQueen, T.S., Lalwani, N. and Ou, J.J. (2019) ACR TIRADS: Pitfalls, Solutions, and Future Directions. RadioGraphics, 39, 2040-2052. https://doi.org/10.1148/rg.2019190026

[7] Baldé, N.M., Baldé, M.D., Kaké, A., Diallo, M.M., Camara, A. and Bah, D. (2007) Hyperthyroïdie à Conakry: Particularités cliniques et thérapeutiques. Annales de 1 Université Marien Ngouabi, 8, 23-17.

[8] Diédhiou, D., Sow, D., Lèye, M.M., Diallo, I.M., Bodian, M., Ndoure, M.A., et al. (2017) 
Cardiothyreosis: Risk Factors and Clinical Profile. Open Journal of Internal Medicine, 7, 1-11. https://doi.org/10.4236/ojim.2017.71001

[9] Camara, A., Baldé, N.M., Diakité, M., Sylla, D., Baldé, E.H., Kengne, A.P. and Baldé, M.D. (2016) High Prevalence, Low Awareness, Treatment, and Control Rates of Hypertension in Guinea: Results from a Population-Based STEPS Survey. Journal of Human Hypertension, 30, 237-244. https://doi.org/10.1038/jhh.2015.92

[10] Sarr, A., Diédhiou, D., Ndour-Mbaye, N.M., Sow, D., Diallo, I.M., Alaoui, S.E., et al. (2016) Graves' Disease in Senegal: Clinical and Evolutionary Aspects. Open Journal of Internal Medicine, 6, 77-82. https://doi.org/10.4236/ojim.2016.63013

[11] Akossou, S.Y., Napporn, A., Goeh-Akue, E., Hillah, A., Sokpoh-Diallo, K., Soussou, B. and Amedegnato, D. (2001) Impairment in the Management of Thyrotoxicosis in Black Africa: The Togolese Experience. Annals of Endocrinology, 62, 516-520.

[12] Dieng, M., Cissé, M., Ndour, M.D., Konaté, I., Touré, A.O., Ka, O., Dia, A. and Touré, C.T. (2010) Indications et résultats des thyroïdectomies réalisées au sein d'un service de chirurgie générale. A propos de 402 patients opérés. Revue Africaine de Chirurgie et Spécialités, 4, 5-10. https://doi.org/10.4314/racs.v4i9.69961 